\title{
Gestão Pública Municipal: um estudo sobre licitação na modalidade pregão no Município de Pesqueira-PE
}

\author{
Municipal Public Management: a study on biddling in the trading modality in the Municipality of \\ Pesqueira-PE \\ Gestión Pública Municipal: estudio de licitación en la modalidad pregão del Municipio de \\ Pesqueira-PE
}

Gabriel Alves de Souza Carvalho ORCID: https://orcid.org/0000-0003-4263-8777 Universidade Federal Rural de Pernambuco, Brasi E-mail: jhompitbull@gmail.com

Emilly Kessia da Costa Cavalcanti ORCID: https://orcid.org/0000-0001-8987-561X Universidade Federal Rural de Pernambuco, Brasil E-mail: emillymillykess@gmail.com

Eliabe Roberto de Souza

ORCID: https://orcid.org/0000-0001-6095-3151 Universidade Federal Rural de Pernambuco, Brasil E-mail: elroso2009@gmail.com

José de Lima Albuquerque

ORCID: https://orcid.org/0000-0003-0625-5656

Universidade Federal Rural de Pernambuco, Brasi E-mail: jose.limaa@ufrpe.br

Rafaela Rodrigues Lins

ORCID: https://orcid.org/0000-0003-4319-5402 Universidade Federal Rural de Pernambuco, Brasil E-mail: rafaela.lins@ufrpe.br

Jorge da Silva Correia Neto ORCID: https://orcid.org/0000-0001-9977-1267 Universidade Federal Rural de Pernambuco, Brasil E-mail: jorgecorreianeto@gmail.com

\begin{abstract}
Resumo
O presente artigo traz uma abordagem sobre as aquisições públicas de bens ou serviços com base nos termos das leis brasileiras em vigor. O objetivo geral desta pesquisa foi investigar como o processo licitatório, na modalidade pregão, tem sido realizado no Município de Pesqueira - PE, no período de 2014-2020. A metodologia utilizada foi a pesquisa documental de caráter qualitativo e os dados secundários foram obtidos no Portal da Transparência de Pesqueira. Os resultados obtidos apontam a predominância da modalidade pregão presencial nos 6 primeiros anos, e a adoção da modalidade pregão eletrônico a partir do primeiro semestre de 2020. Observou-se também que os princípios de base sustentável nas aquisições públicas do município se referem, em sua maioria, às dimensões de sustentabilidade "bemestar social" e "desenvolvimento econômico". Ainda foi constatada a falta de programação de estoques, tendo em vista a existência de editais distintos com a mesma solicitação de aquisição de bens ou serviços. Concluiu-se que as aquisições públicas por meio das licitações, nas modalidades pregão presencial e pregão eletrônico, constituem uma realidade no Município de Pesqueira, porém nos editais de licitação existem a inobservância das bases sustentáveis na aquisição de bens e serviços, assim como se verifica a falta de planejamento dos estoques municipais pela repetição de aquisições públicas.
\end{abstract}

Palavras-chave: Processo licitatório; Base sustentável; Programação de estoques.

\begin{abstract}
This article presents an approach on public acquisitions of goods or services based on the brazilian laws in force. The general objective of this research was to investigate how the bidding process, in the trading mode, has been carried out in the Municipality of Pesqueira - PE, in the period 2014-2020.The methodology used was qualitative documentary research and secondary data were obtained from the Fisheries Transparency Portal. The results obtained indicate the predominance of the face-to-face trading modality in the first 6 years, and the adoption of the electronic trading modality from the first half of 2020.It was also observed that the principles of sustainable basis in public procurement of the municipality refer, mostly, to the dimensions of sustainability "social welfare" and "economic development".
\end{abstract}


The lack of inventory programming was still verified, in view of the existence of different notices with the same request for the acquisition of goods or services. It was concluded that public acquisitions through bidding, in the modalities of face-to-face trading and electronic trading, constitute a reality in the Municipality of Pesqueira, but in the tender notices there is the non-observance of sustainable bases in the acquisition of goods and services, as well as the lack of planning of municipal inventories by the repetition of public acquisitions.

Keywords: Bidding process; Sustainable basis; Inventory scheduling.

\section{Resumen}

Este artículo presenta un enfoque de la contratación pública de bienes o servicios en los términos de las leyes brasileñas vigentes. El objetivo general de esta investigación fue investigar cómo se ha llevado a cabo el proceso de licitación, en la modalidad de subasta, en el Municipio de Pesqueira - PE, en el período 2014-2020. La metodología utilizada fue la investigación documental de carácter cualitativo y los datos secundarios se obtuvieron del Portal de Transparencia de Pesqueira. Los resultados obtenidos muestran el predominio de la modalidad de subasta presencial en los primeros 6 años, y la adopción de la modalidad de subasta electrónica a partir del primer semestre de 2020. También se observó que los principios de una base sustentable en la contratación pública en el municipio se refieren, en su mayor parte, a las dimensiones de sustentabilidad "bienestar social" y "desarrollo económico". También se constató la falta de programación de existencias, ante la existencia de diferentes avisos con una misma solicitud para la adquisición de bienes o servicios. Se concluyó que las adquisiciones públicas a través de licitaciones públicas, en las modalidades de licitación presencial y electrónica, son una realidad en el Municipio de Pesqueira, pero en los pliegos de licitación hay un incumplimiento de las bases sustentables en la adquisición de bienes y servicios, ya que se comprueba la falta de planificación de los stocks municipales debido a la repetición de adquisiciones públicas.

Palabras clave: Proceso de licitación; Base sustentable; Programación de inventarios.

\section{Introdução}

Grande parte das aquisições públicas de bens e serviços no Brasil é disciplinada, primeiramente, pela Constituição da República Federativa do Brasil promulgada em 1988 (CF/88), conforme o inciso XXI do Art. 37, o qual revela que "ressalvados os casos especificados na legislação, as obras, serviços, compras e alienações serão contratados mediante processo de licitação pública [...]” (Brasil, 1988). Mais tarde, em 1993, foi promulgada a Lei n. 8.666, conhecida como "Lei das Licitações”, que institui normas para licitações e contratos da Administração Pública e dá outras providências (Brasil, 1993).

A Lei n.8.666/93 prevê modalidades de licitação como concorrência, tomada de preços, convite, concurso e leilão, e em complementação, no ano de 2002 foi estabelecida a Lei n. 10520, a qual "Institui, no âmbito da União, Estados, Distrito Federal e Municípios, nos termos do inciso XXI do Art. 37, da CF/88, a modalidade de licitação denominada pregão, para aquisição de bens e serviços comuns, e dá outras providências” (Brasil, 2002).

Com o avanço da globalização e das tecnologias da informação e comunicação (TIC), as compras governamentais passaram a ser realizadas através de sistemas eletrônicos auxiliados pela Internet. Dessa forma, visando disciplinar a aquisição de bens e serviços comuns, foi, então, regulamentado o pregão, na forma eletrônica, através do Decreto n. 5.450 de 31 de maio

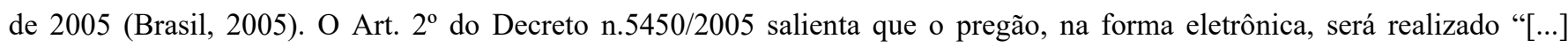
quando a disputa pelo fornecimento de bens ou serviços comuns for feita à distância em sessão pública, por meio de sistema que promova a comunicação pela internet” (Brasil, 2005).

Esta modalidade de pregão vem sendo utilizada nos três níveis da federação, o que inclui os pequenos municípios. Em Pernambuco isso não tem sido diferente. De acordo com o Portal da Transparência do Governo Federal, o Município de Pesqueira, distante $214 \mathrm{~km}$ da capital, recebeu, em 2020, recursos federais na ordem de R\$ 25.152.867,07 (Brasil, 2020). Tomando por base o município citado, o Portal da Transparência, disponibilizado pelo município, revela que foram realizadas 92 solicitações de compras e contratação direta nas modalidades de convite e tomada de preços, e 195 na modalidade pregão presencial, durante o período de janeiro até dezembro de 2019 (Pesqueira, 2020c), mas como foram realizadas as aquisições públicas, na modalidade pregão, no período de 2014 a 2020, no município de Pesqueira-PE? 
Pesquisadores como Muhr (1986), Miyakava (2004), Leite e Rezende (2010), Bona (2015) e Puton (2017) têm se debruçado sobre a temática de gestão pública e licitações, porém, há uma lacuna de conhecimentos no que diz respeito às aquisições públicas, por tipo de licitação, em pequenos municípios. Além disso, o estudo sobre o tema pode possibilitar novos olhares sobre a eficiência e transparência no uso dos recursos públicos na esfera municipal e demais esferas governamentais, seja pelos gestores, pessoal administrativo, acadêmicos e/ou pesquisadores.

Assim, o objetivo geral desta pesquisa se propôs a investigar como o processo licitatório, na modalidade pregão, foi realizado no Município de Pesqueira - PE, no período de 2014-2020. Para alcançar o objetivo geral foram elencados os seguintes objetivos específicos: i) identificar a frequência da modalidade pregão nos editais de licitações de Pesqueira no período entre 2014 a 2020; ii) enunciar os princípios de base sustentável utilizados nas aquisições públicas de Pesqueira e; iii) relatar a existência de programação de estoques para aquisições públicas.

O presente artigo está estruturado em quatro seções, além desta Introdução. A seção de Revisão de Literatura apresenta os fundamentos legais das licitações no Brasil, enquanto a seção Percurso Metodológico discorre sobre a caracterização da pesquisa e sua forma de coleta e análise de dados. Na seção Resultados são discutidos os achados da pesquisa e na seção Considerações Finais são geradas reflexões sobre as conclusões a que se pode chegar.

\section{Revisão de Literatura}

A CF/88 é, sem dúvida, um elemento norteador para balizar as ações administrativas nas esferas municipais, estaduais, federal e no Distrito Federal. No que diz respeito às aquisições públicas de bens e serviços, a CF/88 é enfática ao afirmar que tais ações devem ser balizadas por um instrumento específico denominado licitação.

O inciso XXI do Art. 37da CF/88 revela que, devido às especificidades que são encontradas na lei, as obras, serviços, compras e alienações deverão ser contratadas através de "[...] processo de licitação pública que assegure igualdade de condições a todos os concorrentes, com cláusulas que estabeleçam obrigações de pagamento, mantidas as condições efetivas da proposta, nos termos da lei [...]"' (Brasil, 1988).

O conceito de licitação pode ser apresentado de formas diferentes e sob a ótica de diferentes autores, entre eles Muhr (1986), Costa (2000), e Bona (2015). A "Licitação é uma sucessão ordenada de atos, mediante os quais a administração seleciona a proposta mais vantajosa para a compra do seu interesse" (Muhr, 1986, p. 5), e um "procedimento administrativo, meio técnico legal, uma sucessão ordenada de atos que visam garantir princípios jurídicos consagrados e controladores dos atos do Estado" (Costa, 2000, p.120). Além disso, é um "procedimento administrativo em que os interessados se submetem a regras e exigências estipuladas em edital para aquisição de bens, serviços ou alienações” (Bona, 2015, p. 39). Enfim, é um procedimento utilizado pela administração pública, regido por leis e regras que garantem igualdade na concorrência e permitem que a administração pública escolha a proposta com maior vantagem.

As normas para as licitações são previstas na Lei n. 8.666/93, a qual regulamenta o inciso XXI, do Art. 37, da CF/88, pois a licitação é uma obrigatoriedade constitucional e necessita de regras e normas específicas (Brasil, 1993). O Art. 22 da citada Lei estabelece que a licitação está prevista em cinco diferentes modalidades, a saber: concorrência, tomada de preços, convite, leilão e concurso, como detalha a Figura 1. 
Figura 1 - Modalidades de licitação.

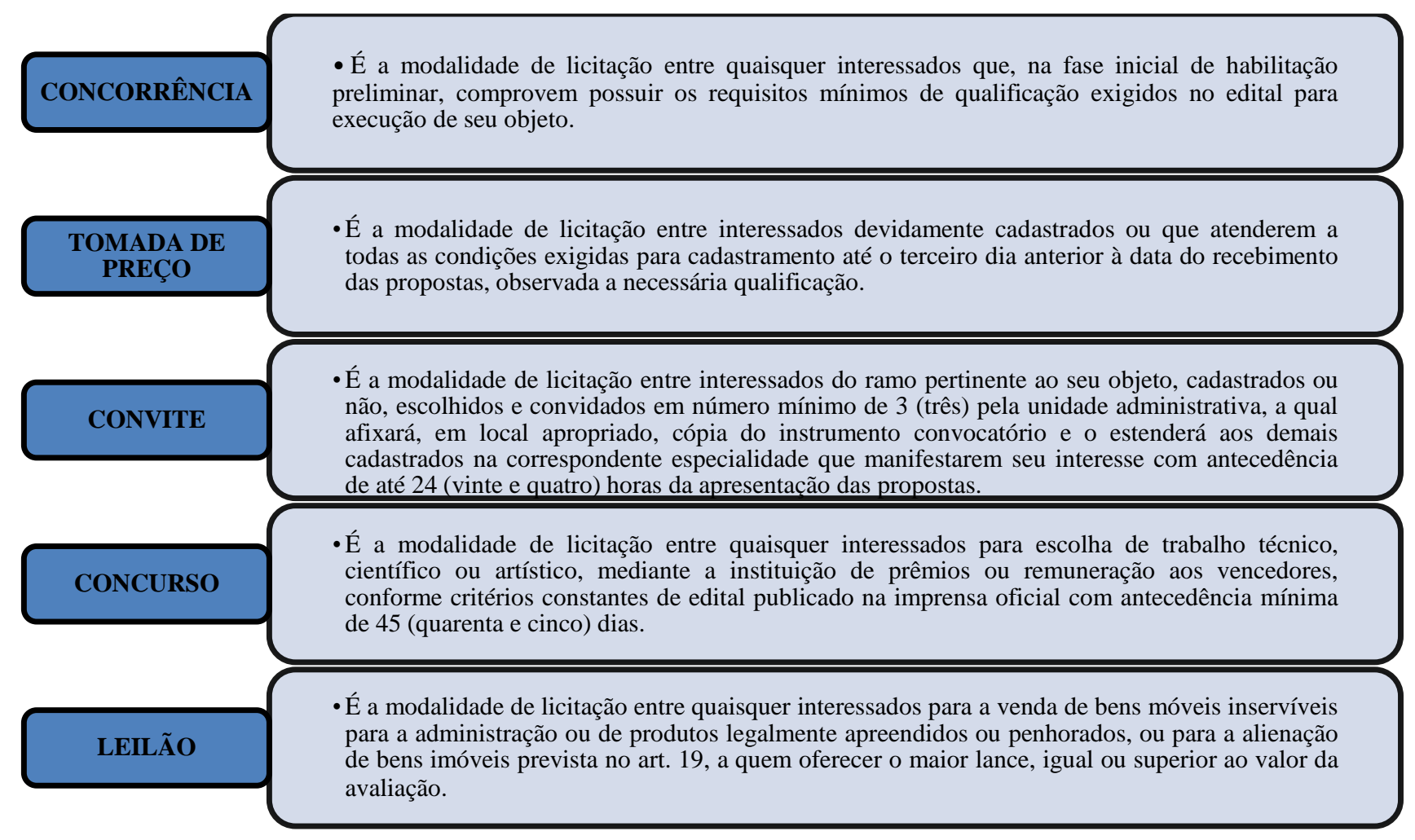

Fonte: Baseada em Brasil (1993).

Além das modalidades definidas pela Lei n. 8.666/93, é importante enfatizar que outra modalidade de licitação foi estabelecida, por meio da Lei n. 10.520/2002, sendo esta modalidade chamada pregão (Brasil, 2002). O pregão, em sua modalidade eletrônica, foi estabelecido através do Decreto n. 5.450/2005, o qual prevê que o seu formato eletrônico irá ocorrer quando a disputa pela oferta de serviços ou bens comuns for realizada em sessão pública e pela internet (Brasil, 2005).

Ainda sobre o Decreto n. 5.450/2005, seus artigos 5 $5^{\circ}$ e 17 trazem informações importantes. O Art. $5^{\circ}$ enfatiza que o pregão é uma modalidade de licitação ligada aos princípios da legalidade, moralidade, impessoalidade, publicidade, igualdade, probidade administrativa, eficiência, vinculação ao instrumento convocatório e do julgamento objetivo, estando atrelado também aos princípios correlatos da razoabilidade, proporcionalidade e competitividade. Já o Art. $6^{\circ}$ demonstra as limitações do pregão no formato eletrônico, dentre as quais estão locações imobiliárias, as contratações de obras de engenharia e alienações em geral. Por fim, no Art. 17 está previsto que o modo de convocação dos interessados na licitação deve ser por publicação de aviso, dependendo do valor estimado para as contratações (Brasil, 2005), como detalha o Quadro 1.

Quadro 1 - Valores estimados da contratação pública.

\begin{tabular}{|c|c|}
\hline VALORES ESTIMADOS & MEIOS DE DIVULGAÇÃO \\
\hline Até R $\$ 650.000,00$ (seiscentos e cinquenta mil reais) & Diário Oficial da União e meio eletrônico na internet \\
\hline $\begin{array}{c}\text { Acima de } \mathrm{R} \$ 650.000,00 \text { (seiscentos e cinquenta mil reais) até } \\
\mathrm{R} \$ 1.300 .000,00 \text { (um milhão e trezentos mil reais) }\end{array}$ & $\begin{array}{c}\text { Diário Oficial da União, meio eletrônico na internet e jornal } \\
\text { de grande circulação local }\end{array}$ \\
\hline $\begin{array}{c}\text { Superiores } \mathrm{R} \$ 1.300 .000,00 \text { (um milhão e trezentos mil reais) } \\
\text { (unario Oficial da União, meio eletrônico na internet e jornal } \\
\text { de grande circulação regional ou nacional }\end{array}$ \\
\hline
\end{tabular}

Fonte: Baseado em Brasil (2005). 
Sobre o pregão, na forma eletrônica, Miyakava (2004) revela que ele ocorre da mesma forma do pregão presencial, contudo se utiliza de recursos tecnológicos, pois não necessita da presença física do pregoeiro e nem dos participantes. Sendo assim, o pregão, na forma eletrônica, apresenta como vantagens a desburocratização no processo de compras dos entes públicos, modernização, aumento da eficiência atrelada à transparência pública e aumento da publicidade.

Neste sentido, Sant'ana (2009, p.59) ainda chama a atenção para o fato da disponibilização das informações públicas, pois auxilia na transparência pública, e cada município deve "[...] gerir de forma adequada suas informações, com especial atenção à questão do acesso público, que deve ser o mais amplo possível, ampliando a transparência da administração e ampliando as possibilidades de participação da sociedade no acompanhamento e controle da gestão da coisa pública".

De fato, ao serem disponibilizadas informações sobre os atos da gestão municipal, de forma explícita e transparente, configura-se então, os princípios de publicidade e eficiência, que devem permear toda a Administração Pública no cumprimento legal da CF de 1988.

Por fim, outro aspecto das compras públicas é trazido à discussão por Biage e Calado (2015). Estes autores afirmam que os processos licitatórios devem levar em consideração os princípios da sustentabilidade, quais sejam: o desenvolvimento econômico, o bem-estar social e a preservação ambiental (Carvalho; Ferreira \& Villac, 2016). Além disso, complementam os citados autores, a licitação sustentável é um instrumento de gestão pública que também leva em conta os direitos humanos.

\section{Percurso Metodológico}

Quanto à classificação da presente pesquisa, o estudo é uma pesquisa aplicada, de cunho qualitativo, que se utilizou da estratégia de estudo de caso intrínseco e coletou dados documentais, tanto físicos como digitais.

Como aponta Santaella (2001, p. 140), as pesquisas aplicadas buscam resolver um problema, partindo de conhecimentos já disponíveis, "mas das aplicações podem resultar não apenas a resolução do problema que a motivou, mas também a ampliação da compreensão que se tem do problema, ou ainda a sugestão de novas questões a serem investigadas". A abordagem qualitativa se mostrou a mais apropriada porque busca dar sentido aos achados sem buscar uma generalização estatística. Além disso, a estratégia de estudo de caso foi escolhida porque se deseja estudar uma unidade social, uma pequena prefeitura, especialmente os seus processos de licitação, profunda e intensamente. "Busca-se apreender a totalidade de uma situação e, criativamente, descrever, compreender e interpretar a complexidade de um caso concreto, mediante um mergulho profundo e exaustivo em um objeto delimitado" (Martins, 2008, p. 8).

Com relação à pesquisa documental, Zanella (2012) destaca que ela pode subsidiar tanto pesquisas qualitativas como quantitativas. A autora explana que os dados secundários poderão ser adquiridos de forma interna em manuais e relatórios da entidade, bem como em relatórios de estoques, nota fiscais, dentre outros, assim como podem ser obtidos de maneira externa, mediante publicações e resultados de pesquisas que já foram desenvolvidas.

\subsection{Local da pesquisa}

O município de Pesqueira está localizado na região Agreste de Pernambuco. Possui limites ao Norte com o Estado da Paraíba e a cidade de Poção, a Leste com as cidades de Belo Jardim, Sanharó, São Bento do Una e Capoeiras, a Oeste com as cidades de Venturosa, Alagoinha, Pedra e Arcoverde. Não há limites com outros municípios ao Sul. Salienta-se que a população estimada do município, no ano de 2019, foi de 67.395 pessoas (Pernambuco, 2019).

A Prefeitura de Pesqueira apresenta a seguinte constituição organizacional: controle interno; entidades supervisionadas; Fundação Zeferino Galvão; Gestão de Transporte (GTRANSP); órgãos de apoio e assessoramento ao prefeito; órgãos consultivos e órgãos de direção (Pesqueira, 2020a). Os órgãos de direção são constituídos por: Secretaria de 
Administração e Assuntos Jurídicos; Secretaria de Agricultura; Secretaria de Articulação Institucional e Controle Interno; Secretaria de Assistência Social e Cidadania; Secretaria de Finanças; Secretaria de Governo e Planejamento; Secretaria de Cultura e Turismo; Secretaria de Educação; Secretaria de Infraestrutura; Secretaria de Meio Ambiente; Secretaria de Saúde e Secretaria Municipal de Esportes e Juventude (Pesqueira, 2020b).

\subsection{Coleta de dados}

A coleta de dados foi feita no site da Prefeitura de Pesqueira, o qual apresenta um painel geral referente ao Portal da Transparência municipal. O painel do Portal da Transparência do Município de Pesqueira é constituído por 17 painéis, sendo eles: Receitas; Despesas; Empenhos e restos a pagar; Licitações; Avisos de licitações; Prestação de contas; Leis e decretos; Ouvidoria; Gestão de Pessoas; Organograma; E-SIC autoatendimento; Leis Orçamentárias Anuais (LOA); Lei de Diretrizes Orçamentárias (LDO); Planos Plurianuais (PPP); Regulação da LAI; FAQ e Tributos (Pesqueira, 2020c).

Dentre os painéis mencionados, o foco foi o painel "Licitações", constituído por abas específicas, a saber: Processos Licitatórios; Contratos; Leis e Decretos; Atos de Pessoal; e Compra/Contratação Direta (Pesqueira, 2020c). A pesquisa foi realizada com dados da aba "Processos Licitatórios", a qual contempla os editais de processos de licitações, contratos e outros atos administrativos (Pesqueira, 2020c).

\subsection{Análise dos dados}

Os dados secundários foram obtidos no mês de janeiro de 2021, referente à série história das licitações no período de 2014 até 2020. A análise dos dados foi realizada mediante análise de conteúdo, que de acordo com Campos (2004) é entendida como conjunto de técnicas de pesquisa que têm a finalidade de buscar por sentido ou sentidos de um documento. Logo, realiza análises em forma de comunicação, fazendo referência a tudo que constitui o texto e enfatizando a relevância da semântica para o uso do método.

A análise de conteúdo foi baseada em unidades de análise temáticas. Segundo Campos (2004), "o evidenciamento das unidades de análise temáticas, que são recortes do texto, consegue-se segundo um processo dinâmico e indutivo de atenção ora concreta a mensagem explícita, ora as significações não aparentes do contexto". O autor evidencia que as unidades de análise temáticas são interdependentes dos objetivos do estudo, bem como com as teorias adotadas na pesquisa.

Assim, a análise de conteúdo da pesquisa repousou em categorias de análise temática como forma de extrair significados dos editais na modalidade pregão do período de 2014 a 2020.

\section{Resultados}

A pesquisa sobre gestão pública municipal e licitação na modalidade pregão foi uma atividade com o propósito de investigar como o processo licitatório, na modalidade pregão, tem sido realizado no Município de Pesqueira - PE, no período de 2014-2020.

A primeira ação investigativa, no tocante ao desenvolvimento do processo licitatório, foi identificar a frequência da modalidade pregão nos editais de licitações no município de Pesqueira no período entre os anos de 2014 e 2020. A importância da frequência ou da repetição deste ato de compra reflete na eficiência do processo de compras públicas, na transparência pública e na ampliação dos atos de publicidade. Sendo assim, uma síntese dos dados obtidos nos editais de licitação do Município de Pesqueira está disposta nas Figuras 2 e 3. 
Figura2 - Frequência da modalidade Pregão Presencial no período de 2014 a 2020.

\begin{tabular}{|c|c|c|c|c|c|c|c|c|c|c|c|c|c|}
\hline \multirow{3}{*}{\multicolumn{2}{|c|}{ 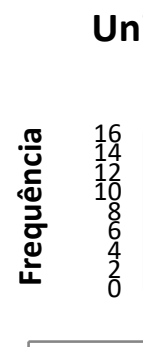 }} & \\
\hline & & & \multicolumn{11}{|c|}{ Unidades de análise: compras públicas e negociações eletrônicas } \\
\hline & & Jan & Fev. & Mar. & Abr & Maio & Jun & Jul & Ago. & Set & Out. & Nov. & Dez. \\
\hline & 2014 & 1 & 7 & 4 & 7 & 3 & 7 & 2 & 7 & 7 & 4 & 1 & 0 \\
\hline & 2015 & 0 & 1 & 5 & 6 & 4 & 3 & 6 & 7 & 2 & 1 & 2 & 0 \\
\hline & 2016 & 2 & 1 & 7 & 3 & 4 & 6 & 0 & 0 & 0 & 0 & 3 & 1 \\
\hline & 2017 & 1 & 7 & 15 & 13 & 11 & 6 & 3 & 6 & 8 & 4 & 2 & 8 \\
\hline & 2018 & 8 & 3 & 11 & 8 & 7 & 5 & 11 & 5 & 5 & 4 & 2 & 1 \\
\hline & 2019 & 2 & 9 & 8 & 2 & 9 & 4 & 4 & 5 & 3 & 1 & 1 & 4 \\
\hline & 2020 & 14 & 5 & 0 & 0 & 0 & 0 & 0 & 0 & 0 & 0 & 0 & 0 \\
\hline
\end{tabular}

Fonte: Elaborada pelos autores a partir de Pesqueira-Licitações (2014-2020).

Figura 3 - Frequência da modalidade Pregão Eletrônico no período de 2014 a 2020.

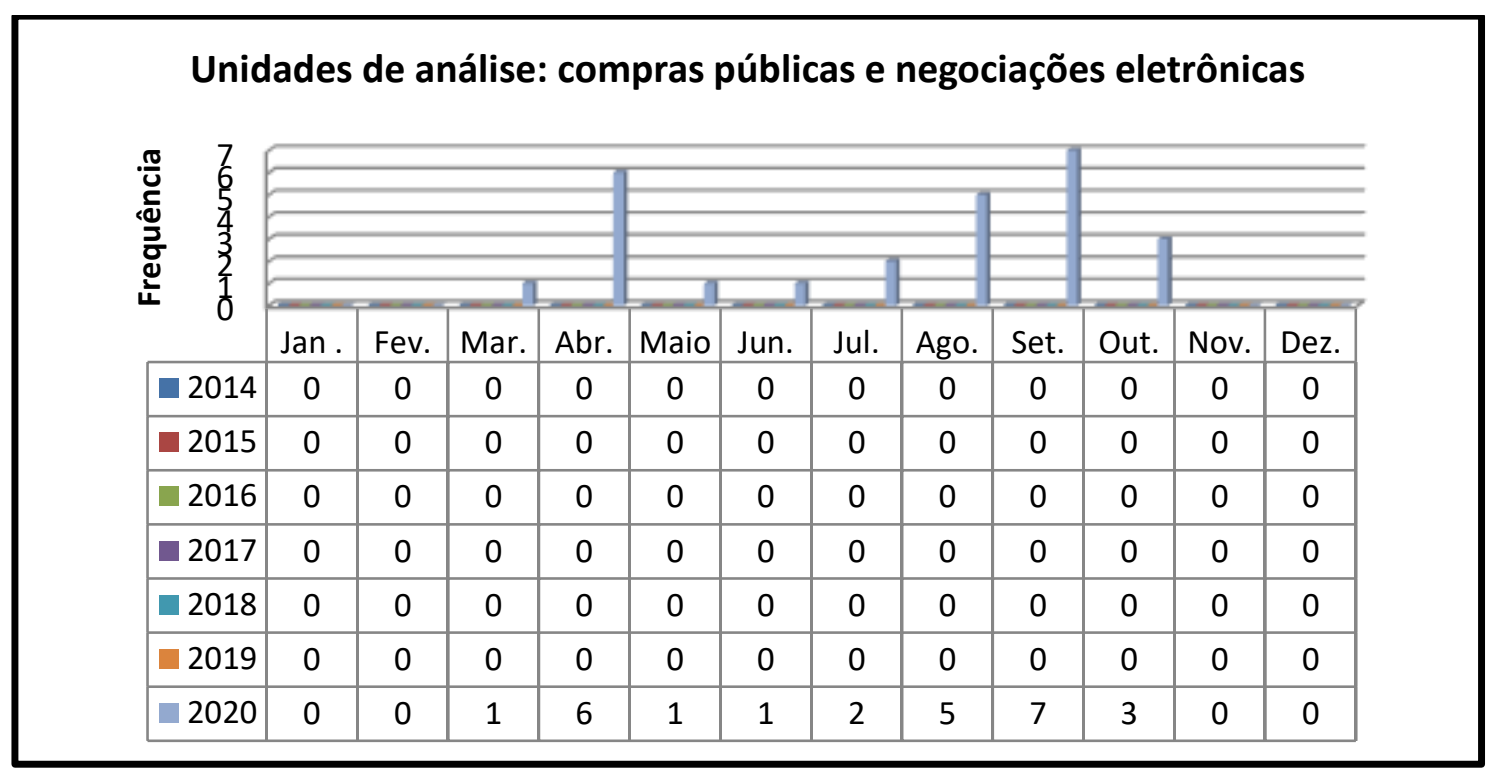

Fonte: Elaborada pelos autores a partir de Pesqueira-Licitações (2014-2020).

De acordo com os dados das Figuras 2 e 3, se percebe que a modalidade pregão, na forma presencial, sobressai durante os 7 (sete) anos da série histórica apresentada, ou seja, de 2014 até 2019, a modalidade pregão presencial é predominante, especialmente no ano de 2017, em que ocorreram 84 editais de licitação.

Por outro lado, a modalidade pregão eletrônico não foi realizada entre os anos de 2014 até 2019, muito embora essa modalidade de licitação tenha sido regulamentada em 2005, sendo, porém, realizada no ano de 2020, a partir do mês de março até o mês de outubro, no total de 26 editais licitações.

Na série histórica apresentada, os anos que mais apresentaram a modalidade pregão foram respectivamente, o ano de 2017 com 84 editais de licitação, o ano de 2018 com 70 editais e o ano de 2019 com 52 editais de licitação. Já, os anos de 2015 
e 2016, foram os anos que menos tiveram processos licitatórios na modalidade pregão, com 37 editais no ano de 2015 e 27 editais no ano de 2016.

No que diz respeito às aquisições por semestre, percebeu-se que no primeiro semestre dos anos de 2017, 2018 e 2019 ocorreram mais pregões, sendo 53 editais em 2017, 42 editais em 2018 e 34 editais em 2019. Em relação aos semestres que tiveram menos editais de licitação, foram o segundo semestre dos anos de 2015 e 2019 com 18 editais cada, o segundo semestre de 2020 com 17 editais, todos na modalidade pregão eletrônico, e o segundo semestre de 2016 com 4 editais.

Em toda a série histórica da pesquisa, o ano de 2017 foi o que mais teve licitações na modalidade pregão e o mês com maior número de editais de licitação foi o mês de março de 2017, com 15 licitações na referida modalidade.

Registra-se ainda que entre os anos de 2014 até 2020, ocorreram 365 (trezentas e sessenta e cinco) licitações, nas modalidades pregão presencial e pregão eletrônico. Em percentuais, no ano de 2014 houve 14\% das 365 licitações, já no ano de 2015 houve 10\%, o ano de 2016 teve 7\%, em 2017 ocorreram 23\% de todas as licitações dentre todos os anos, o ano de 2018 teve $19 \%$, o ano de 2019 teve $14 \%$, e, por fim, o ano de 2020 apresentou $12 \%$ de todas as licitações em estudo. Ficou evidente que o maior percentual das licitações ocorreu no ano de 2017 e o menor no ano de 2016, com uma diferença aproximada de $16 \%$.

A segunda ação investigativa foi enunciar princípios de base sustentável nas aquisições públicas no Município de Pesqueira. Dessa maneira, os dados obtidos nos editais licitatórios estão apresentados no Quadro 2.

Quadro 2 - Princípios de base sustentável nas aquisições públicas em Pesqueira - PE.

\begin{tabular}{|c|c|c|c|c|}
\hline \multicolumn{5}{|c|}{ UNIDADE DE ANÁLISE: aquisições públicas de bases sustentáveis } \\
\hline \multirow[b]{3}{*}{ Ano } & \multirow[b]{3}{*}{ Edital } & \multicolumn{3}{|c|}{ Dimensões de Sustentabilidade } \\
\hline & & Bem-Estar Social & Desenvolvimento Econômico & Preservação Ambiental \\
\hline & & $\begin{array}{c}\text { Produtos baseados na consciência } \\
\text { ambiental; uso de mão de obra } \\
\text { local; uso do princípio de } \\
\text { isonomia; saúde e segurança no } \\
\text { trabalho; fornecimento de } \\
\text { equipamento de proteção } \\
\text { individual. }\end{array}$ & $\begin{array}{l}\text { Maior geração de empregos; } \\
\text { menor custo de manutenção; } \\
\text { maior vida útil, menor custo e } \\
\text { proposta mais vantajosa para o } \\
\text { setor público, redução de } \\
\text { resíduos sólidos urbanos e } \\
\text { logística reversa. }\end{array}$ & $\begin{array}{l}\text { Menor impacto sobre recursos } \\
\text { naturais; tecnologias e } \\
\text { matérias-primas de origem } \\
\text { local; material reciclado, } \\
\text { biodegradável, atóxico e de } \\
\text { reflorestamento; atividades } \\
\text { não poluentes, redução do } \\
\text { consumo de água e energia. }\end{array}$ \\
\hline 2014 & $\begin{array}{l}001 \text { a } 037 \\
040,041 \text { e } \\
043 / 2014\end{array}$ & $\begin{array}{c}\text { "Será assegurado, como critério } \\
\text { de desempate, preferência de } \\
\text { contratação para as } \\
\text { microempresas e empresas de } \\
\text { pequeno porte" (Editais 001, 013, } \\
021 \text { e } 031 / 2014)\end{array}$ & $\begin{array}{l}\text { “O Pregoeiro poderá negociar } \\
\text { com o autor da oferta de } \\
\text { menor valor com vistas à } \\
\text { redução do preço” (Editais } \\
\text { 001/2014; 013/2014, 021/2014, } \\
\text { 031/2014) }\end{array}$ & Não apresenta a dimensão \\
\hline 2015 & $\begin{array}{c}001 \text { a } 017 \\
019 \text { a } 023 \\
025 \text { a } \\
026 / 2015\end{array}$ & $\begin{array}{c}\text { “Após a etapa de lances, sendo } \\
\text { verificada a ocorrência de } \\
\text { empate ficto, será assegurada, } \\
\text { como critério de desempate, } \\
\text { preferência de contratação para } \\
\text { as Microempresas e Empresas de } \\
\text { Pequeno Porte, nos termos da } \\
\text { Lei Complementar no } 123 / 2006 ” \\
\text { (Editais } 001 \text { a 017; } 019 \text { a } 023 \text { e } \\
\text { 026/2015). }\end{array}$ & $\begin{array}{l}\text { “A Pregoeira poderá negociar } \\
\text { diretamente com a licitante } \\
\text { para que seja obtido preço } \\
\text { melhor”. (Editais 001 a 017; } \\
019 \text { a } 023 \text { e 026/2015). }\end{array}$ & Não apresenta a dimensão \\
\hline 2016 & $\begin{array}{c}001 \text { a } 017 \\
019 \text { a } \\
025 / 2016\end{array}$ & $\begin{array}{l}\text { “Após a etapa de lances, sendo } \\
\text { verificada a ocorrência de } \\
\text { empate ficto, será assegurada, } \\
\text { como critério de desempate, } \\
\text { preferência de contratação para }\end{array}$ & $\begin{array}{c}\text { "A Pregoeira poderá negociar } \\
\text { diretamente com a licitante } \\
\text { para que seja obtido preço } \\
\text { melhor" (Editais } 001 \text { a } 017 ; \\
\text { 019 a 025/2016). }\end{array}$ & Não apresenta a dimensão \\
\hline
\end{tabular}




\begin{tabular}{|c|c|c|c|c|}
\hline & & $\begin{array}{l}\text { as Microempresas e Empresas de } \\
\text { Pequeno Porte, nos termos da } \\
\text { Lei Complementar } n^{\circ} 123 / ; 2006 " \\
\text { (Editais 001 a } 017 ; 019 \text { a } \\
\text { 0252016). }\end{array}$ & & \\
\hline 2017 & $\begin{array}{c}001 \mathrm{a} \\
061 / 2017\end{array}$ & $\begin{array}{c}\text { “Após a etapa de lances, sendo } \\
\text { verificada a ocorrência de } \\
\text { empate ficto, será assegurada, } \\
\text { como critério de desempate, } \\
\text { preferência de contratação para } \\
\text { as Microempresas e Empresas de } \\
\text { Pequeno Porte, nos termos da } \\
\text { Lei Complementar n } n^{\circ} 123 / ; 2006 " \\
\text { (Editais 001 a 015, 017 a } 019 ; \\
030 \text { a 034; 051 a 057, } 059 \text { a } \\
\text { 061/2017). }\end{array}$ & $\begin{array}{l}\text { "O Pregoeiro poderá negociar } \\
\text { diretamente com a licitante } \\
\text { para que seja obtido preço } \\
\text { melhor" (Editais } 001 \text { a 015, } \\
017 \text { a 019; 024 a 025; 027; } \\
\text { 030; 032 a 036; 051 a 057; } \\
\text { 059 a 061/2017). }\end{array}$ & $\begin{array}{l}\text { “[...] é justificada, tendo em } \\
\text { vista as situações potenciais } \\
\text { de riscos permanentes, que o } \\
\text { mesmo representa para a } \\
\text { saúde pública e ao meio } \\
\text { ambiente, bem como, pela } \\
\text { obrigatoriedade, de atender a } \\
\text { legislação vigente no que se } \\
\text { refere ao gerenciamento de } \\
\text { Resíduos de Serviços de } \\
\text { Saúde” (Edital 029/2017). }\end{array}$ \\
\hline 2018 & $\begin{array}{c}001 \mathrm{a} \\
041 / 2018\end{array}$ & $\begin{array}{c}\text { “[...] a participação das } \\
\text { microempresas e empresas de } \\
\text { pequeno porte, terão tratamento } \\
\text { diferenciado e favorecido a ser } \\
\text { dispensado no âmbito dos } \\
\text { Poderes da União, dos Estados, } \\
\text { do Distrito Federal e dos } \\
\text { Municípios, especialmente no } \\
\text { que se refere à preferência nas } \\
\text { aquisições de bens e serviços } \\
\text { pelos Poderes Públicos [...]” } \\
\text { (Editais 001 a 004; 010 a 022; } \\
\text { 026 a 027; 029; 031 1 040/2018). }\end{array}$ & $\begin{array}{l}\text { “O Pregoeiro poderá negociar } \\
\text { com o autor da oferta de } \\
\text { menor valor com vistas à } \\
\text { redução do preço”(Editais } 001 \\
\text { a 027; 029 a 041/2018). }\end{array}$ & $\begin{array}{l}\text { “A profissionalização dos } \\
\text { eventos desse município é } \\
\text { uma demanda estratégica } \\
\text { para o planejamento de } \\
\text { desenvolvimento do turismo } \\
\text { da cidade, de forma } \\
\text { sustentável e organizada é de } \\
\text { fundamental importância } \\
\text { oferecer eventos cada vez } \\
\text { maiores e com alto nível de } \\
\text { profissionalismo” (Edital } \\
\text { O01/2018). }\end{array}$ \\
\hline 2019 & $\begin{array}{c}001 \mathrm{a} \\
023 / 2019\end{array}$ & $\begin{array}{c}\text { “Na presente licitação será } \\
\text { assegurada, como critério de } \\
\text { desempate, preferência de } \\
\text { contratação para as } \\
\text { microempresas e empresas de } \\
\text { pequeno porte" (Editais } 001 \text { a } \\
003 ; 006 \text { a } 012 ; 014 \text { a } 021 ; \\
023 / 2019)\end{array}$ & $\begin{array}{l}\text { “O Pregoeiro poderá negociar } \\
\text { diretamente com a licitante } \\
\text { detentora da proposta de } \\
\text { menor preço por item, no } \\
\text { sentido de que seja obtido } \\
\text { melhor preço” (Editais } 001 \text { a } \\
\text { 021/2019; 023/2019) }\end{array}$ & Não apresenta a dimensão \\
\hline 2020 & $\begin{array}{c}001 \mathrm{a} \\
017 / 2020\end{array}$ & $\begin{array}{l}\text { "Na presente licitação será } \\
\text { assegurada, como critério de } \\
\text { desempate, preferência de } \\
\text { contratação para as } \\
\text { microempresas e empresas de } \\
\text { pequeno porte" (Editais } 001 \text { a } \\
\text { 006; 010/2020). }\end{array}$ & $\begin{array}{l}\text { "O Pregoeiro poderá negociar } \\
\text { com o autor da oferta de } \\
\text { menor valor com vistas à } \\
\text { redução do preço". (Editais } \\
\text { 001 a 011/2020). }\end{array}$ & Não apresenta a dimensão \\
\hline
\end{tabular}

Fonte: Elaborado pelos autores a partir de Pesqueira-Licitações (2014-2020).

De acordo com os dados do Quadro 2, percebe-se indicativos de sustentabilidade em todos os certames da série em estudo, havendo predominância para as dimensões de sustentabilidade "Bem-estar Social" e "Desenvolvimento Econômico".

Segundo o "Guia Nacional de Licitações Sustentáveis", publicado pela Advocacia-Geral da União, redigido por Carvalho, Ferreira e Villac (2016), para que uma licitação seja considerada sustentável, deve apresentar as dimensões "Bemestar Social", "Desenvolvimento Econômico" e "Preservação Ambiental". Sendo assim, foi possível identificar no ano de 2017, todas as dimensões de sustentabilidade, porém nenhum dos certames apresentou as 3 (três) dimensões no mesmo edital de pregão. O ano de 2018, por sua vez, se destaca nesse sentido, avançando e apresentando no edital 001/2018 todas as dimensões, ou seja, uma licitação plenamente sustentável. Contudo, esse avanço não se perpetuou, apresentando um retrocesso nos anos de 
2019 e 2020, os quais não constam as 3 (três) dimensões, voltando a dar ênfase aos indicativos de bem-estar social e ao desenvolvimento econômico.

Assim, tal retrocesso representa o uso inadequado do Tesouro público e, por conseguinte, a falta de atendimento das demandas da sociedade, diante disso, verifica-se a importância de um certame apresentar todas as dimensões de sustentabilidade.

A terceira ação investigativa tratou de relatar a existência de programação de estoques para as aquisições públicas no município de Pesqueira. Desta forma, os dados adquiridos nos certames são expostos no Quadro 3.

Quadro 3 - Existência de programação de estoques para as aquisições públicas em Pesqueira-PE.

\begin{tabular}{|c|c|c|c|c|}
\hline \multicolumn{5}{|c|}{ UNIDADE DE ANÁLISE: planejamento de aquisições públicas } \\
\hline ANO & EDITAIS & AQUISIÇÕES & REPETIÇÃO & $\begin{array}{l}\text { TIPO DE } \\
\text { PREGÃO }\end{array}$ \\
\hline 2014 & 026 e 027 & $\begin{array}{l}\text { Contratação de Pessoa Jurídica para prestar serviços de } \\
\text { comunicação multimídia (SCM) serviço de internet (SCI) } \\
\text { suportando aplicações TCP/IP com velocidade conforme } \\
\text { especifica no termo de referência, para o HLP, Atenção Básica, } \\
\text { NASF, CAPS, vigilância em saúde, até dia 31/12/2014. (Editais } \\
026 \text { e 027) }\end{array}$ & 2 & $\begin{array}{c}\text { Pregão } \\
\text { Presencial }\end{array}$ \\
\hline 2015 & 005 e 011 & $\begin{array}{l}\text { Aquisição de combustível e lubrificantes, entre outros: álcool, } \\
\text { gasolina, óleo combustível, óleo diesel comum, diesel s10 e } \\
\text { graxa lubrificante, óleo hidráulico e etc, para atender as } \\
\text { necessidades do hospital DR. Lídio Paraíba, SAMU, Atenção } \\
\text { Básica, epidemiologia, vigilância em saúde, até o dia } 31 \text { de } \\
\text { dezembro de } 2015 \text { (Editais O05 e 011). }\end{array}$ & 2 & $\begin{array}{c}\text { Pregão } \\
\text { Presencial }\end{array}$ \\
\hline 2016 & $\begin{array}{l}\text { Não apresenta } \\
\text { repetição de } \\
\text { termo de } \\
\text { referência }\end{array}$ & Não apresenta repetição de termo de referência & 0 & $\begin{array}{c}\text { Pregão } \\
\text { Presencial }\end{array}$ \\
\hline 2017 & 012 e 080 & $\begin{array}{l}\text { Prestação de serviços para realizar processos de seleção } \\
\text { simplificada para preenchimento de funções públicas junto as } \\
\text { Secretarias Municipais, na forma do Quadro de Servidores da } \\
\text { Prefeitura Municipal de Pesqueira/PE. (Editais } 012 \text { e 080). }\end{array}$ & 2 & $\begin{array}{c}\text { Pregão } \\
\text { Presencial }\end{array}$ \\
\hline 2018 & $\begin{array}{l}\text { Não apresenta } \\
\text { repetição de } \\
\text { termo de } \\
\text { referência }\end{array}$ & Não apresenta repetição de termo de referência & 0 & $\begin{array}{c}\text { Pregão } \\
\text { Presencial }\end{array}$ \\
\hline 2019 & $\begin{array}{l}\text { Não apresenta } \\
\text { repetição de } \\
\text { termo de } \\
\text { referência }\end{array}$ & Não apresenta repetição de termo de referência & 0 & $\begin{array}{c}\text { Pregão } \\
\text { presencial }\end{array}$ \\
\hline 2020 & 014 e 017 & $\begin{array}{c}\text { Aquisição de Equipamentos Permanentes de uso Médico, } 20 \\
\text { (vinte) Eletrocardiógrafos para atender as necessidades da } \\
\text { Atenção Básica, em conformidade com as especificações e } \\
\text { quantidades estabelecidas no Termo de Referência (Anexo II) e } \\
\text { anexo do edital. (Edital 014/2020 e 017/2020). }\end{array}$ & 2 & $\begin{array}{l}\text { Editais } 014 \\
\quad \text { e } 017 \\
\text { (Pregão } \\
\text { eletrônico) }\end{array}$ \\
\hline
\end{tabular}

Fonte: Baseado em Pesqueira-Licitações (2014-2020).

De acordo com os dados apresentados no Quadro 3, se percebe que do ano de 2014 até 2020, nenhum ano se destacou por possuir mais repetições de editais de pregões. Os anos de 2014, 2015, 2017 e 2020, possuem cada um, somente duas repetições de licitações na modalidade pregão. 
Chama atenção o fato de algumas licitações se repetirem no mesmo ano, especialmente as que tratam de contratação de serviços de multimídia (2014), aquisição de combustíveis (2015), prestação de serviço para seleção simplificada (2018) e aquisição de equipamentos médicos permanentes (2020).

Já nos anos de 2016 e 2018, não existe repetição de editais de pregão com o mesmo termo de referência, fato que comprova que para esses dois anos houve programação de estoques no município e uso adequado do erário, visto que a repetição de aquisições públicas em um mesmo exercício aponta para a falta de programação e planejamento de estoques. Logo, se vê a necessidade do planejamento de estoques ou serviços para a administração pública municipal, tendo em vista que cada pregão possui um custo para a Administração Pública. Em contrapartida, a adoção do estoque zero, isto é, daquilo que é extremamente necessário para uso dentro das atividades do serviço público, se torna uma forma eficiente e eficaz de gerenciar os recursos públicos e, assim, maximizar o atendimento das necessidades da sociedade pesqueirense.

\section{Considerações Finais}

A investigação sobre licitações na modalidade pregão no Município de Pesqueira-PE procurou responder como foram realizadas as aquisições públicas, por meio de licitações, na modalidade pregão, no Município de Pesqueira no período de 2014 a 2020 .

Em resposta ao problema de pesquisa percebe-se a predominância da licitação na modalidade pregão presencial nos 6 (seis) primeiros anos e a adoção da modalidade pregão eletrônico a partir do primeiro semestre de 2020. Os princípios de base sustentável em todas as aquisições públicas de Pesqueira, na modalidade pregão, parecem estar relacionados apenas às dimensões "bem-estar social” e "desenvolvimento econômico", excluindo-se a dimensão "preservação ambiental”. Destaca-se somente um edital de base plenamente sustentável, ou seja, que engloba as três dimensões, no ano de 2018. Destaca-se, ainda, a falta de programação anual de estoques, pelo fato de haver editais distintos com a mesma solicitação de aquisição de bens ou serviços.

Sendo assim, conclui-se que as aquisições públicas por meio das licitações, nas modalidades pregão presencial e pregão eletrônico, constituem uma realidade no município estudado, porém nos editais de licitação há inobservância das bases sustentáveis na aquisição de bens e serviços, assim como se verifica a falta de planejamento dos estoques municipais pela repetição de aquisições públicas.

As limitações do estudo ocorreram devido à dificuldade de acesso aos dados, pelo fato do período pós-eleitoral e da mudança de gestão no Município de Pesqueira-PE, causando instabilidade e indisponibilidade de dados no Portal da Transparência de Pesqueira. Como futuros estudos, se sugere abordagens sobre a conformidade das contratações diretas no município, verificando editais de inexigibilidade e dispensa de licitação.

O foco desta pesquisa esteve voltado para licitação na modalidade pregão, contudo outros estudos podem ser realizados com outras modalidades de licitação, as quais não foram contempladas nesta pesquisa, pelo fato de a temática ser de grande importância na formação de futuros pesquisadores da Administração Pública, orientação para os gestores públicos no uso do erário e no atendimento efetivo das demandas da sociedade.

\section{Referências}

Biage, V. S. M. \& Calado, L. R. (2015). Análise dos Resultados das Contratações Públicas Sustentáveis. Revista Eletrônica de Administração, 21(3), 601-621.

Bona, C. P. (2015). Pregão eletrônico e o princípio da eficiência: um estudo de caso da comissão permanente de licitações de materiais da Prefeitura do Recife (Dissertação de Mestrado em Gestão Pública para o Desenvolvimento do Nordeste). Universidade Federal de Pernambuco, Recife, Brasil.

Brasil. (1988). Constituição da República Federativa do Brasil de 1988. Brasília, DF: Presidência da República. http://www.planalto.gov.br/ccivil_03/constituicao/constituicao.htm. 
Brasil. (1993). Lei $n^{\circ}$ 8.666, de 21 de junho de 1993. Regulamenta o art. 37, inciso XXI, da Constituição Federal, institui normas para licitações e contratos da Administração Pública e dá outras providências. http://www.planalto.gov.br/ccivil_03/leis/18666cons.htm.

Brasil. (2002). Lei $n^{\circ}$ 10.520, de 17 de julho de 2002. Institui, no âmbito da União, Estados, Distrito Federal e Municípios, nos termos do art. 37, inciso XXI, da Constituição Federal, modalidade de licitação denominada pregão, para aquisição de bens e serviços comuns, e dá outras providências http://www.planalto.gov.br/ccivil_03/LEIS/2002/L10520.htm.

Brasil. (2005). Decreto n. 5.450, de 31 de maio de 2005. Regulamenta o pregão, na forma eletrônica, para aquisição de bens e serviços comuns, e dá outras providências. http://www.planalto.gov.br/ccivil_03/_ato2004-2006/2005/decreto/d5450.htm.

Brasil. (2020). Controladoria-Geral da União. Portal da Transparência. Localidades. Relação de Municípios: Pesqueira 2020. http://www.port altransparencia.gov.br/localidades.

Campos, C. J. G. (2004). Método de Análise de Conteúdo: ferramenta para a análise de dados qualitativos no campo da saúde. Revista Brasileira de Enfermagem, Brasília, 57(5) 611-614.

Carvalho, F. G., Ferreira, M. A. S. O., \& Villac, T. (2016). Guia Nacional de Licitações Sustentáveis. AGU.

Costa, A. L. (2000). Sistemas de compras privadas e públicas no Brasil. Revista de Administração, 35(4), $119-128$.

Leite, L. O., \& Rezende, D. A. (2010). Modelo de gestão municipal baseado na utilização estratégica de recursos da tecnologia da informação para a gestão governamental: formatação do modelo e avaliação em um município. Revista de Administração Pública, 44(2), 459-493.

Martins, G. A. (2008). Estudo de caso: uma reflexão sobre a aplicabilidade em pesquisas no Brasil. Revista de Contabilidade e Organizações, 2(2), 8-18.

Miyakava, G. T. (2004). Pregão presencial e eletrônico: análise dos fatores competitivos (Dissertação de Mestrado em Engenharia de Produção). Universidade Federal de Santa Catarina, Florianópolis, Brasil.

Muhr, E. (1986). Os critérios de julgamento das licitações. Revista de Administração de Empresas, 26(2), 5-11.

Pernambuco. (2019). Base de Dados do Estado [BDE]. Cadernos Municipais. http://www.bde.pe.gov.br/estruturacaogeral/filtroCadernoEstatistico.aspx.

Pesqueira. (2020a). Governo Municipal de Pesqueira. Organograma. https://pesqueira.pe.gov.br/organograma/.

Pesqueira. (2020b). Governo Municipal de Pesqueira. Institucional. https://pesqueira.pe.gov.br/.

Pesqueira. (2014-2020). Portal da Transparência. Processos Licitatórios 2014-2020. http://cloud.publica.inf.br/clientes/pesqueira_pm/portaltransparen cia/?p=4\&inic io=01/01/2019\&fim=31/12/2019\&param=Gid42XKb9UVjG\%2FCpq5HSVvUXPOoZbXR5DpJDEDFSP1s\%3D.

Pesqueira. (2020c). Portal da Transparência. Processos Licitatórios 2020. http://cloud.publica.inf.br/clientes/pesqueira_pm/portaltransparencia/?p=4\&ini cio=01/01/2019 \&fim=31/12/201 9\&param=Gid42XKb9UVjG\%2FCpq5HSVvUXPOoZbXR5DpJDEDFSP1s\%3D.

Puton, R. (2017). Aspectos críticos na condução do pregão eletrônico: uma abordagem a partir da opinião de pregoeiros da UFES (Dissertação de Mestrado em Gestão Pública). Universidade Federal do Espírito Santo, Vitória, Brasil.

Sant'ana, R. C. G. (2009). Tecnologia e gestão pública municipal: mensuração da interação com a sociedade. São Paulo: Editora UNESP; São Paulo: Cultura Acadêmica.

Santaella, L. (2001) Comunicação e pesquisa: projetos para mestrado e doutorado. Hacker Editores.

Zanella, L. C. H. (2012). Metodologia de estudo e de pesquisa em administração. Departamento de Ciências da Administração / UFSC. 